\title{
BMJ Open Biologic Treatment Registry Across Canada (BioTRAC): a multicentre, prospective, observational study of patients treated with infliximab for ankylosing spondylitis
}

Proton Rahman, ${ }^{1}$ Denis Choquette, ${ }^{2}$ William G Bensen, ${ }^{3,4}$ Majed Khraishi, ${ }^{5}$ Andrew Chow, ${ }^{6}$ Michel Zummer, ${ }^{7,8}$ Saeed Shaikh, ${ }^{9}$ Maqbool Sheriff, ${ }^{10}$ Sanjay Dixit, ${ }^{9}$ Dalton Sholter, ${ }^{11}$ Eliofotisti Psaradellis, ${ }^{12,13}$ John S Sampalis, ${ }^{12,13}$ Vincent Letourneau, ${ }^{14}$ Allen J Lehman, ${ }^{14}$ François Nantel, ${ }^{14}$ Emmanouil Rampakakis, ${ }^{12,13}$ Susan Otawa, ${ }^{14}$ May Shawi ${ }^{14}$

To cite: Rahman $P$, Choquette D, Bensen WG, et al. Biologic Treatment Registry Across Canada (BioTRAC): a multicentre, prospective, observational study of patients treated with infliximab for ankylosing spondylitis. BMJ Open 2016;6:e009661. doi:10.1136/bmjopen-2015009661

- Prepublication history for this paper is available online. To view these files please visit the journal online (http://dx.doi.org/10.1136/ bmjopen-2015-009661).

Received 7 August 2015 Revised 5 November 2015 Accepted 10 December 2015

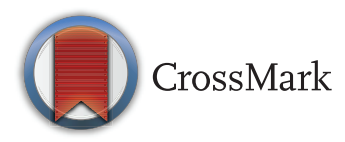

For numbered affiliations see end of article.

Correspondence to Dr Proton Rahman; prahman@mun.ca

\section{ABSTRACT}

Objectives: To describe the profile of patients with ankylosing spondylitis (AS) treated with infliximab in Canadian routine care and to assess the effectiveness and safety of infliximab in real world.

Setting: 46 primary care rheumatology practices across Canada.

Participants: 303 biological-naïve patients with AS or patients previously treated with a biological for $<6$ months and who were eligible for infliximab treatment as per routine care within the Biologic Treatment Registry Across Canada (BioTRAC). Intervention: Not applicable (non-interventional study).

Primary and secondary outcomes: Effectiveness was assessed with changes in disease parameters (AS Disease Activity Score (ASDAS), Bath AS Disease Activity Index (BASDAI), Bath AS Functional Index (BASFI), Health Assessment Questionnaire Disease Index (HAQ-DI), physician global assessment of disease activity (MDGA), patient global disease activity (PtGA), back pain, C-reactive protein, erythrocyte sedimentation rate (ESR), morning stiffness). Safety was assessed with the incidence of adverse events (AEs).

Results: Of the 303 patients included, $44.6 \%$ were enrolled in 2005-2007 and 55.4\% in 2008-2013. Patients enrolled in 2005-2007 had significantly higher MDGA and ESR at baseline while all other disease parameters examined were numerically higher with the exception of PtGA. Treatment with infliximab significantly $(p<0.001)$ improved all disease parameters over time in both groups. At 6 months, $56 \%$ and $31 \%$ of patients achieved clinically important (change $\geq 1.1$ ) and major (change $\geq 2.0$ ) improvement in ASDAS, respectively; at 48 months, these proportions increased to $75 \%$ and $50 \%$, respectively. Among patients unemployed due to disability at baseline, $12.1 \%$ returned to work (mean Kaplan-Meier (KM)-based time=38.8 months). The estimated retention rate at 12 and 24 months was $78.3 \%$

\section{Strengths and limitations of this study}

- To our knowledge, this is the first study assessing the burden of illness of ankylosing spondylitis in a real-world setting in Canada.

- The large number of patients seen in a real-world setting during routine clinical practice enhances the generalisability of the data to the target population.

- Examination of radiographic progression was not possible as radiographic images are not collected in Biologic Treatment Registry Across Canada (BioTRAC).

- Completer analysis was used for the assessment of clinical and patient outcomes; therefore, the treatment effect may have been overestimated because of the healthy worker effect.

- Safety was assessed with the incidence of physician and patient-reported adverse events at every follow-up which may have led to underestimated rates due to patient recall bias.

and $60.1 \%$, respectively. The profile and incidence of AEs were comparable to data previously reported for tumour necrosis factor- $\alpha$ inhibitors.

Conclusions: Characteristics of patients with AS at infliximab initiation changed over time towards lower disease activity and shorter disease duration. Infliximab treatment significantly reduced disease activity independent of treatment initiation year, although patients enrolled in recent years achieved lower disease activity over 48 months.

Trial registration number: NCT00741793.

\section{INTRODUCTION}

Ankylosing spondylitis (AS) is the prototype of spondyloarthropathies (SpA), a group of 
diseases presenting with inflammation of the axial skeleton, peripheral arthritis and enthesitis (inflammation at insertion site of tendons, ligaments and joint capsules). ${ }^{1}$ Extra-articular manifestations of AS include inflammatory bowel disease, anterior uveitis and psoriasis. ${ }^{2}$ The disease generally manifests in the second to third decade of life. ${ }^{3}{ }^{4}$ The prevalence of AS is estimated to be as high as $0.9 \%$ and affects between 150000 and 300000 people in Canada. ${ }^{5}$ Studies have shown that AS is associated with a significant economic burden which is directly associated with disease severity, in particular deteriorating physical function. ${ }^{6-9}$ Compared with the general population, individuals with AS have lower employment rates, experience more disability and are more frequently absent from work. ${ }^{10-12}$

Currently, there is no cure for AS, but early diagnosis and treatment may control the clinical symptoms and minimise joint damage. ${ }^{13}$ Traditional therapies, including non-steroidal anti-inflammatory drugs (NSAIDs) and physiotherapy have been the mainstay for treatment of AS. ${ }^{14}$ Although these therapies remain the first-line treatment option, a substantial proportion of patients cannot be sufficiently treated with NSAID therapy alone. $^{15}$ Similarly, despite the efficacy of diseasemodifying anti-rheumatic drugs (DMARDs) in rheumatoid arthritis (RA), their impact on disease progression is only modest in patients with axial SpA, particularly those with AS. ${ }^{16} 17$ Apart from NSAIDs and physiotherapy, no therapeutic agent with proven efficacy in AS was available until the introduction of antitumour necrosis factor $\alpha(\mathrm{TNF}-\alpha)$ agents. Treatment with infliximab (IFX), an anti-TNF- $\alpha$ agent, has been shown to result in significant improvements in disease activity (Bath AS Disease Activity Index, BASDAI), functional index (Bath AS Functional Index, BASFI) and spinal mobility (Bath AS Metrology Index, BASMI) ${ }^{18-21}$ Moreover, the clinical efficacy of IFX has been substantiated by magnetic resonance imaging (MRI) studies showing a clear reduction in acute inflammation in the spine and sacroiliac joints. ${ }^{19} 2223$

Although the salient features of diagnostic criteria for AS are radiographic sacroiliitis and symptoms and signs of axial arthritis, this is problematic because structural changes may only become apparent after 6-8 years of disease activity. ${ }^{24-28}$ Furthermore, MRI is not recommended for the assessment of back pain in routine care due to its high cost. ${ }^{29}$ This diagnostic delay may result in a decreased effectiveness to TNF- $\alpha$ inhibitors, where disease duration has been established as a predictor of response. ${ }^{30}$

A paucity of literature exists discussing the efficacy and tolerability of anti-TNF- $\alpha$ in routine clinical practice. Post-approval clinical studies allow the assessment of the real-world effectiveness of treatments on the target population treated under routine care. Moreover, ongoing long-term surveillance for safety signals under routine clinical practice is necessary for the detection of rare, but potentially serious adverse events (SAEs).
Using data from the Biologic Treatment Registry Across Canada (BioTRAC), the current analysis describes the profile of patients with AS over time treated with IFX in Canada and describes the effectiveness and the safety of IFX in routine clinical practice.

\section{METHODS}

\section{Study design}

BioTRAC is an ongoing prospective, multicentre, observational registry collecting real-world clinical, laboratory, patient-centric and safety data in patients with RA, AS and psoriatic arthritis treated with IFX or golimumab (GLM) as part of their routine care. The historical development of the registry has been described by Thorne $e t a l .{ }^{31}$ To date, there are over 70 rheumatology sites participating, both in an institutional and private setting, with over 1800 patients enrolled in the programme across all indications. In accordance with the observational nature of the registry, there is no protocoldefined intervention in the patient management and all clinical decisions, including anti-TNF initiation, and treatments are based on routine practice and the judgement of the treating physicians. Patients provided written informed consent prior to participation in the study. Ethics approvals for participation in the BioTRAC program were obtained from the respective Research Ethics Boards (REB) of participating institutional sites and a Central Institutional Review Board (IRB Services, Ontario Canada) for private practice sites. BioTRAC is conducted according to the tenets of the Declaration of Helsinki.

\section{Study population}

Biological-naïve patients or patients previously treated with a biological for $<6$ months and who are eligible for treatment with IFX or GLM as per the Canadian Product Monograph are considered for inclusion in the registry. For the purpose of the current analysis, patients with AS who initiated treatment with IFX between 2005 and 2013 were included. In order to examine differences in patient characteristics over time, the cohort was divided in two almost equal subgroups, those enrolled between 2005 and 2007 vs those enrolled between 2008 and 2013. All effectiveness analyses were performed in the modified intent-to-treat (mITT) population comprising all enrolled patients who received at least one dose of IFX and had at least one follow-up assessment $(\mathrm{N}=303)$. Safety analysis was based on the safety population including all patients who received at least one dose of IFX $(\mathrm{N}=320)$.

\section{Data collection}

The following clinical parameters and patient-reported outcomes were collected by the treating physician: morning stiffness, AS Disease Activity Score (ASDAS), BASDAI, BASFI, Health Assessment Questionnaire Disease Index (HAQ-DI), physician global assessment of 
disease activity (MDGA), patient global disease activity (PtGA), back pain, C-reactive protein (CRP) value and erythrocyte sedimentation rate (ESR) value. PtGA and back pain were based on the Assessment of SpondyloArthritis International Society (ASAS) core set. Safety was assessed with the incidence of AEs.

\section{Statistical analysis}

Descriptive statistics including measures of central tendency (mean, median) and dispersion (SD, 95\% CIs of the mean) were presented for continuous patient characteristics and clinical outcome measures. Frequency distributions were produced for categorical variables.

Table 1 Patient demographics and baseline characteristics

\begin{tabular}{|c|c|c|c|c|}
\hline \multirow[b]{2}{*}{ Parameter } & \multicolumn{2}{|c|}{ Enrolment period } & \multirow[b]{2}{*}{$\begin{array}{l}\text { Total } \\
\mathrm{N}=303\end{array}$} & \multirow[b]{2}{*}{$\begin{array}{l}\text { p Value* } \\
\text { (between groups) }\end{array}$} \\
\hline & $\begin{array}{l}2005-2007 \\
N=135\end{array}$ & $\begin{array}{l}2008-2013 \\
N=168\end{array}$ & & \\
\hline \multicolumn{5}{|l|}{ Demographics } \\
\hline Male gender, n (\%) & $82(60.7)$ & $107(63.7)$ & $189(62.4)$ & 0.634 \\
\hline Age, years, mean (SD) & $45.6(11.6)$ & $45.7(11.9)$ & $45.6(11.7)$ & 0.958 \\
\hline \multicolumn{5}{|l|}{ Baseline characteristics } \\
\hline Disease duration, years, mean (SD) & $11.1(10.8)$ & $8.2(9.2)$ & $9.6(10.0)$ & 0.011 \\
\hline Unemployed, n (\%)† & $62(45.9)$ & $77(46.7)$ & 139 (46.3) & 0.908 \\
\hline Unemployed due to disability, n (\%)‡ & $29(46.8)$ & $37(48.1)$ & 66 (47.5) & $>0.999$ \\
\hline \multicolumn{5}{|l|}{ Financial coverage, $n(\%) \dagger$} \\
\hline Public & $38(28.1)$ & 67 (41.9) & $105(35.6)$ & 0.012 \\
\hline Private & $71(52.6)$ & $70(43.8)$ & $141(47.8)$ & \\
\hline Public and private & $10(7.4)$ & $16(10.0)$ & $26(8.8)$ & \\
\hline Other & $16(11.9)$ & $7(4.4)$ & $23(7.8)$ & \\
\hline IFX dose (mg/kg), mean (SD) & $4.3(1.0)$ & $4.4(1.2)$ & $4.4(1.1)$ & 0.372 \\
\hline Number of previous DMARDs, mean (SD) & $0.7(1.1)$ & $0.5(0.8)$ & $0.6(0.9)$ & 0.078 \\
\hline \multicolumn{5}{|l|}{ Previous therapy, n (\%) } \\
\hline DMARDs & $56(41.5)$ & $56(33.3)$ & $112(37.0)$ & 0.152 \\
\hline NSAIDs & 97 (71.9) & $125(74.4)$ & $222(73.3)$ & 0.695 \\
\hline Corticosteroids & $37(27.4)$ & $46(27.4)$ & $83(27.4)$ & $>0.999$ \\
\hline Methotrexate & $33(24.4)$ & $40(23.8)$ & $73(24.1)$ & 0.894 \\
\hline \multicolumn{5}{|l|}{ Concomitant therapy, n (\%) } \\
\hline DMARDs & $37(27.4)$ & $50(29.8)$ & $87(28.7)$ & 0.702 \\
\hline NSAIDs & 72 (53.3) & $99(58.9)$ & $171(56.4)$ & 0.352 \\
\hline Corticosteroids & $9(6.7)$ & $6(3.6)$ & $15(5.0)$ & 0.288 \\
\hline Methotrexate & $28(20.7)$ & $41(24.4)$ & $69(22.8)$ & 0.492 \\
\hline NSAIDs, previous or concomitant therapy, $\mathrm{n}(\%)$ & $116(85.9)$ & $130(77.4)$ & $246(81.2)$ & 0.075 \\
\hline ASDAS, mean (SD) & $3.9(0.9)$ & $3.7(1.1)$ & $3.8(1.0)$ & 0.103 \\
\hline \multicolumn{5}{|l|}{ ASDAS disease activity, $\mathrm{n}(\%) \dagger$} \\
\hline Inactive $(<1.3)$ & $0(0.0)$ & $4(3.1)$ & $4(1.7)$ & 0.160 \\
\hline Moderate (1.3-2.0) & $1(1.0)$ & $3(2.3)$ & $4(1.7)$ & \\
\hline High $(2.1-3.5)$ & $34(33.0)$ & $50(38.5)$ & $84(36.1)$ & \\
\hline Very high (>3.5) & $68(66.0)$ & $73(56.2)$ & $141(60.5)$ & \\
\hline BASDAI, mean (SD) & $6.5(1.9)$ & $6.4(2.2)$ & $6.4(2.0)$ & 0.490 \\
\hline BASFI, mean (SD) & $6.3(2.2)$ & $6.1(2.5)$ & $6.2(2.4)$ & 0.447 \\
\hline HAQ-DI, mean (SD) & $1.3(0.6)$ & $1.2(0.6)$ & $1.2(0.6)$ & 0.318 \\
\hline AM stiffness ${ }^{\S}$, minutes, mean (SD) & $79.0(38.9)$ & $70.1(42.4)$ & $74.1(41.0)$ & 0.064 \\
\hline MDGA (NRS: 0-10), mean (SD) & $7.0(1.6)$ & $6.3(2.1)$ & $6.6(1.9)$ & 0.001 \\
\hline PtGA (NRS: 0-10), mean (SD) & $6.6(2.3)$ & $6.7(2.4)$ & $6.7(2.3)$ & 0.811 \\
\hline Back pain (NRS: 0-10), mean (SD) & $6.7(2.5)$ & $6.5(2.6)$ & $6.6(2.6)$ & 0.623 \\
\hline $\mathrm{ESR}(\mathrm{mm} / \mathrm{h})$, mean $(\mathrm{SD})$ & $30.0(23.1)$ & $19.9(18.1)$ & $24.5(21.1)$ & $<0.001$ \\
\hline $\mathrm{CRP}(\mathrm{mg} / \mathrm{L})$, mean (SD) & $20.4(23.9)$ & $16.7(25.7)$ & $18.3(24.9)$ & 0.243 \\
\hline
\end{tabular}

*Statistically significant values are marked in italics.

†Percentages based on patients who provided a response: employment $(n=300)$; financial coverage $(n=295)$; ASDAS disease activity $(n=233)$.

$\ddagger$ Percentage based on total number of unemployed patients $(n=139)$.

§Capped at $120 \mathrm{~min}$.

AM stiffness, morning stiffness; ASDAS, Ankylosing Spondylitis Disease Activity Score; BASDAl, Bath Ankylosing Spondylitis Disease Activity Index; BASFI, Bath Ankylosing Spondylitis Functional Index; CRP, C-reactive protein; DMARDs, disease-modifying antirheumatic drugs; ESR, erythrocyte sedimentation rate; HAQ-DI, Health Assessment Questionnaire Disease Index; IFX, infliximab; MDGA, physician global assessment of disease activity; NRS, Numeric Rating Scale; NSAIDs, non-steroidal anti-inflammatory drugs; PtGA, patient global disease activity. 
Between-group differences in patient baseline characteristics and demographics across enrolment periods were assessed for statistical significance using the $\chi^{2}$ statistic for categorical parameters and the independent-samples $\mathrm{t}$ test for continuous parameters. Within-group improvements in continuous disease parameters over time were assessed with linear mixed-effects models. The Kaplan-Meier (KM) estimator of the survival function was used to assess the durability of the treatment and time to employment; comparisons between subgroups were made with the log-rank test. AEs were classified according to the Medical Dictionary for Regulatory Activities (MedDRA V.13.0) and summarised using the total number of AEs, the total number and percentage of patients who experience an $\mathrm{AE}$ overall and by body system and preferred term. AE relationship to the study medication was based on the judgement of the treating physician. All statistical tests were two-sided, with a $\mathrm{p}$ value of 0.05 or less considered to indicate statistical significance. Statistical analyses were conducted with SPSS V.12.0 (SPSS Inc, Chicago, Illinois, USA) and SAS V.9.2 (SAS Institute, Cary, North Carolina, USA).
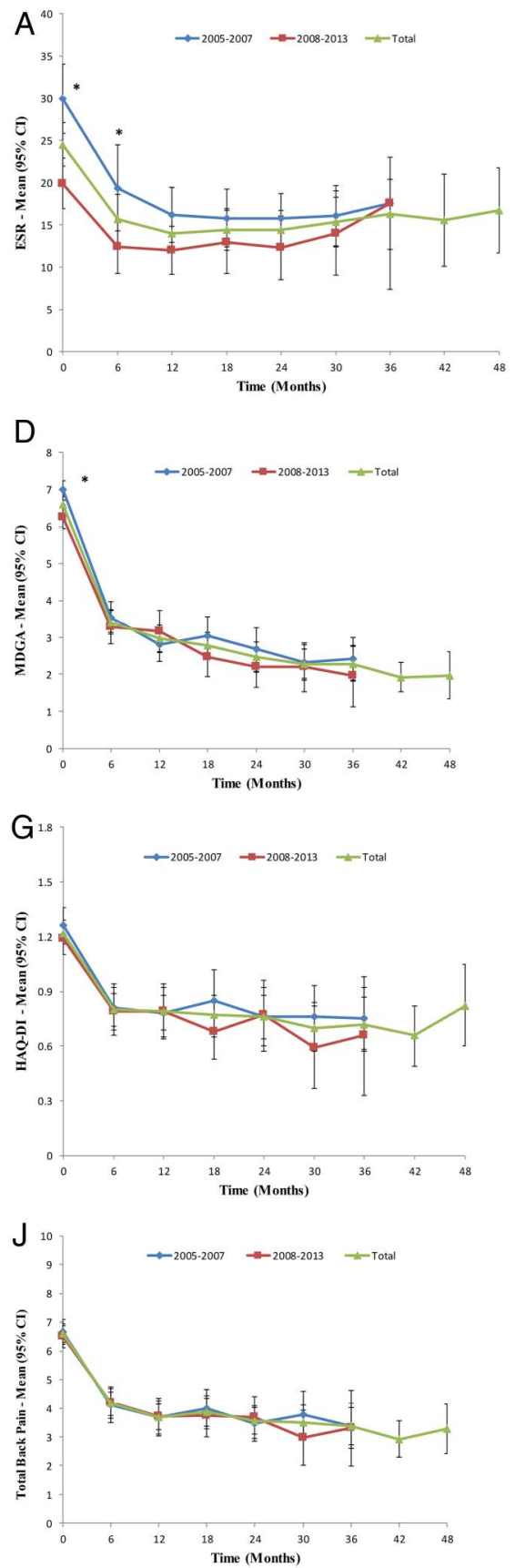

B

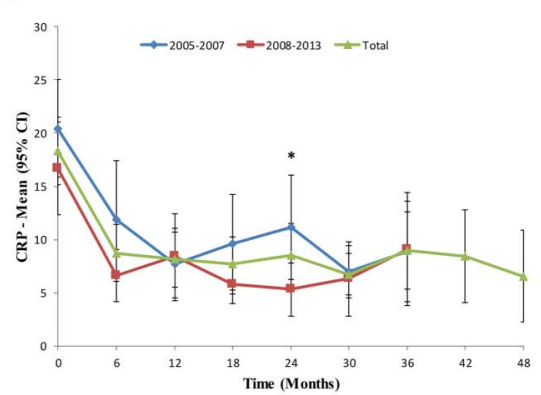

E

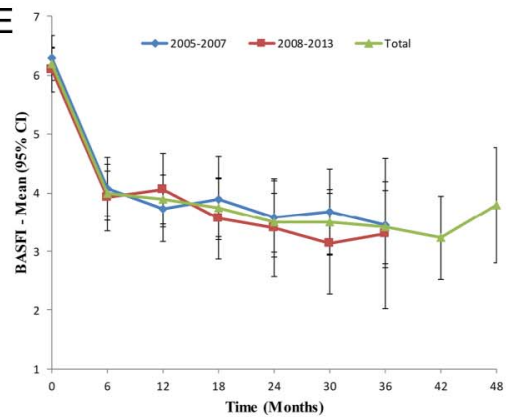

$\mathrm{H}$

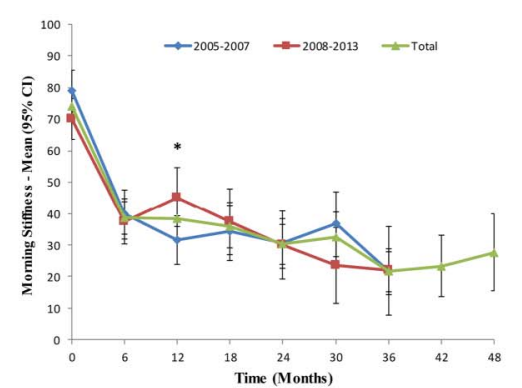

C
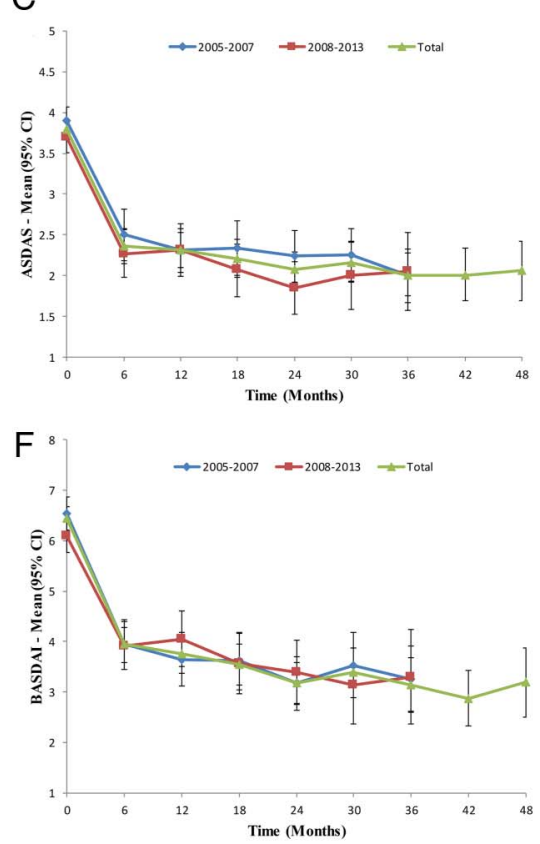

I

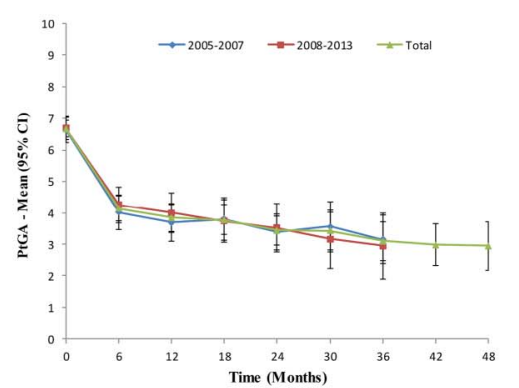

Figure 1 Disease parameters over time. The total number of patients attending the 6-month, 12-month, 18-month, 24-month, 30-month, 36-month, 42-month and 48-month assessment was 215, 167, 136, 116, 97, 74, 52 and 38, respectively. *Denotes statistically significant difference between subgroups. 


\section{RESULTS}

Patient demographics, characteristics and treatment parameters

A total of 303 patients with AS were included in the mITT population. Patient demographics and baseline characteristics are summarised in table 1 for the total cohort and by enrolment period (2005-2007 and 20082013). There were $189(62.4 \%)$ males, mean (SD) age was 45.6 (11.7) years and mean (SD) disease duration was 9.6 (10.0) years. Patients recruited in recent years had significantly lower disease duration (8.2 vs 11.1 years; $\mathrm{p}=0.011)$. At baseline, $139(46.3 \%)$ of patients were unemployed. Among these, disability was the predominant reason for unemployment $(47.5 \%)$, while other reasons included retirement (18.7\%), being a homemaker $(8.6 \%)$, or a student $(4.3 \%)$, and temporary leave of absence (4.3\%). A significant relationship was observed between financial coverage and enrolment period $(\mathrm{p}=0.012)$, with public coverage being significantly higher (41.9\% of patients) in the 2008-2013 enrolment period relative to $2005-2007$ (28.1\% of patients).

Previous use of NSAID, DMARD, corticosteroid and methotrexate therapy was reported by $73.3 \%, 37.0 \%$, $27.4 \%$ and $24.1 \%$ of patients, respectively. At IFX initiation, $56.4 \%, 28.7 \%, 22.8 \%$ and $5.0 \%$ of patients were treated with concomitant NSAIDs, DMARDs, methotrexate and corticosteroids, respectively. Furthermore, previous or concomitant use of NSAIDs was reported by $81.2 \%$ of patients. No significant differences were observed for previous and concomitant therapy use between enrolment periods.

Overall, baseline disease parameters were numerically lower for the most recent enrolment period (20082013) relative to the first period (2005-2007), with the
Figure 2 (A) Ankylosing Spondylitis Disease Activity Score (ASDAS) clinically important improvement over time. (B) ASDAS major improvement over time. The percentages are based on completers.
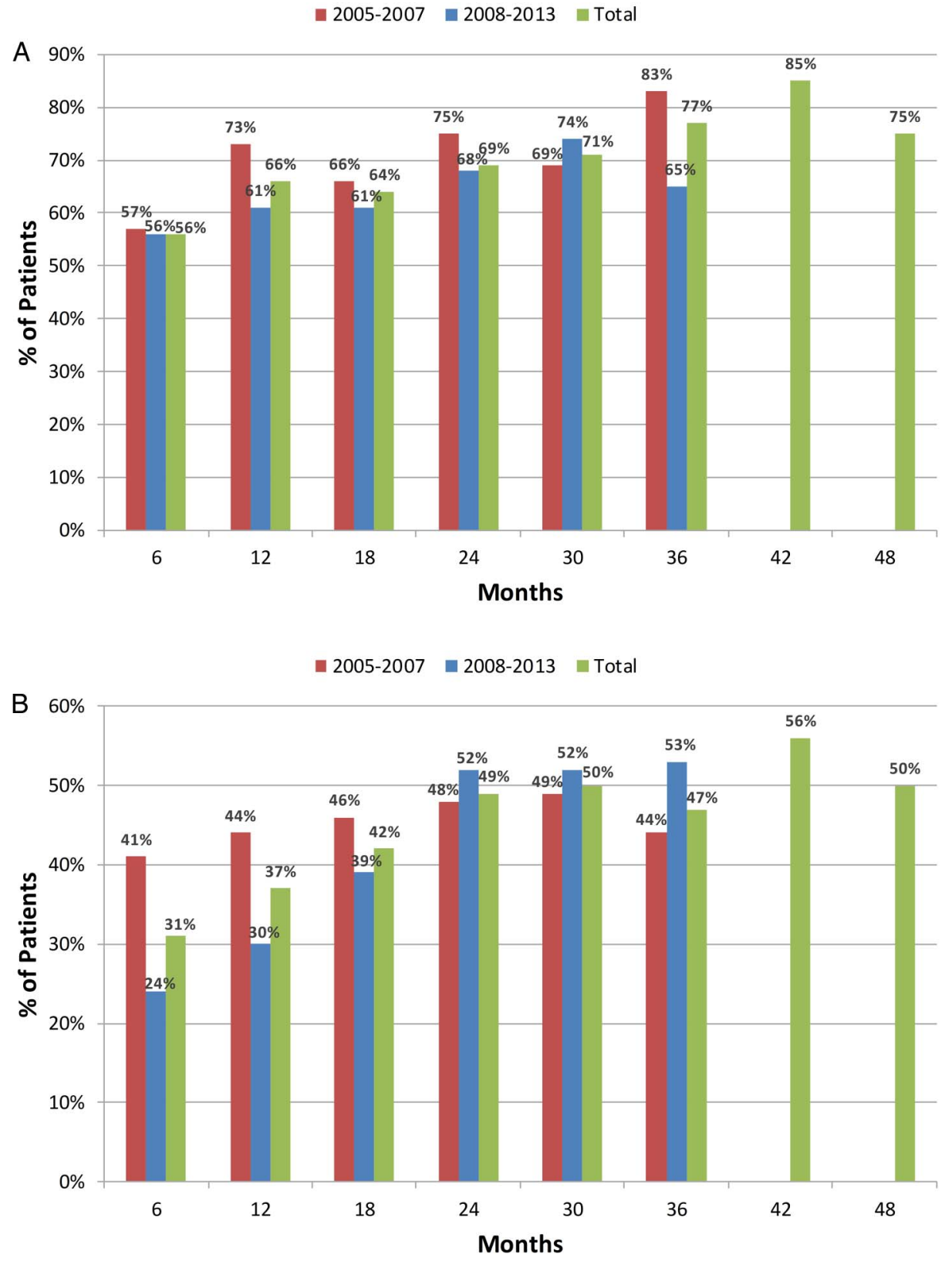
following parameters showing a statistical difference between the two groups: ESR $(19.9$ vs $30.0 \mathrm{~mm} / \mathrm{h}$; $\mathrm{p}<0.001$ ), MDGA (6.3 vs 7.0; $\mathrm{p}=0.001$ ). No significant differences were observed for BASDAI, BASFI, HAQ-DI, PtGA, back pain and CRP between enrolment periods.

In the overall population, the majority of patients had very high $(60.5 \%)$, or high $(36.1 \%)$, ASDAS disease activity at baseline.

\section{Effectiveness outcomes}

The disease parameters over 48 months of treatment with IFX are summarised in figure 1. Statistically significant $(\mathrm{p}<0.001)$ and clinically meaningful improvement was observed for all disease parameters evaluated including ESR, CRP, ASDAS, BASFI, BASDAI, HAQ-DI, MDGA, PtGA, back pain and morning stiffness at 6 months of treatment and was further sustained over 48 months. Regression analysis showed that patients enrolled in 2008-2013 had significantly lower disease activity over time compared with those enrolled in 2005-2007 as indicated by the statistically lower ESR $(p<0.001$; figure $1 \mathrm{~A})$, CRP $(p=0.027$; figure 1B), ASDAS ( $p=0.046$; figure 1C) and MDGA ( $p=0.012$; figure 1D). No significant differences in BASFI (figure 1E), BASDAI (figure $1 \mathrm{~F}$ ), HAQ-DI (figure 1G), morning stiffness (figure $1 \mathrm{H}$ ), PtGA (figure 1I) and back pain (figure 1J) were observed over time between enrolment periods. By 6, 12, 24, 36 and 48 months, $56 \%, 66 \%, 72 \%, 77 \%$ and $75 \%$, respectively, of patients achieved clinically important improvement in ASDAS (change $\geq 1.1$; figure $2 \mathrm{~A}$ ); major improvement (change $\geq 2.0$ ) in ASDAS was achieved by $31 \%, 37 \%, 49 \%, 47 \%$ and $50 \%$, respectively. No statistically significant differences were observed between the two groups in terms of meeting ASDAS end points. Achievement of ASDAS major improvement was faster within the earlier enrolment period (figure 2B) which could be due to the higher baseline ASDAS in this group.

The proportion of patients employed at baseline was $53.7 \%$. Of these patients, $3(1.9 \%)$ patients became unemployed due to disability during the course of the follow-up. Among patients unemployed due to disability at baseline, $8(12.1 \%)$ patients returned to work after a mean (95\% CI) KM-based time of 38.8 (33.2-44.4) months.

\section{Discontinuations, safety and tolerability}

A total of 320 patients received at least one dose of IFX and were included in the safety population. After an average of 19.3 months of follow-up, 104 (32.5\%) patients discontinued from the study. Reasons for discontinuation included: lack/loss of response $(n=34$; $10.6 \%)$, $\mathrm{AE}(\mathrm{n}=28 ; 8.8 \%)$, loss to follow-up $(\mathrm{n}=11$; $3.4 \%)$, withdrawal of consent $(n=10 ; 3.1 \%)$, geographic issues $(\mathrm{n}=6 ; 1.9 \%)$, disease progression $(\mathrm{n}=4 ; 1.3 \%)$, patient received other therapy $(\mathrm{n}=4 ; 1.3 \%)$, financial reasons $(n=3 ; 0.9 \%)$, complete response $(n=2 ; 0.6 \%)$ and other $(\mathrm{n}=2 ; 0.6 \%)$. Using survival analysis, mean $(95 \% \mathrm{CI})$ time to discontinuation was 43.0 (38.7-47.3)

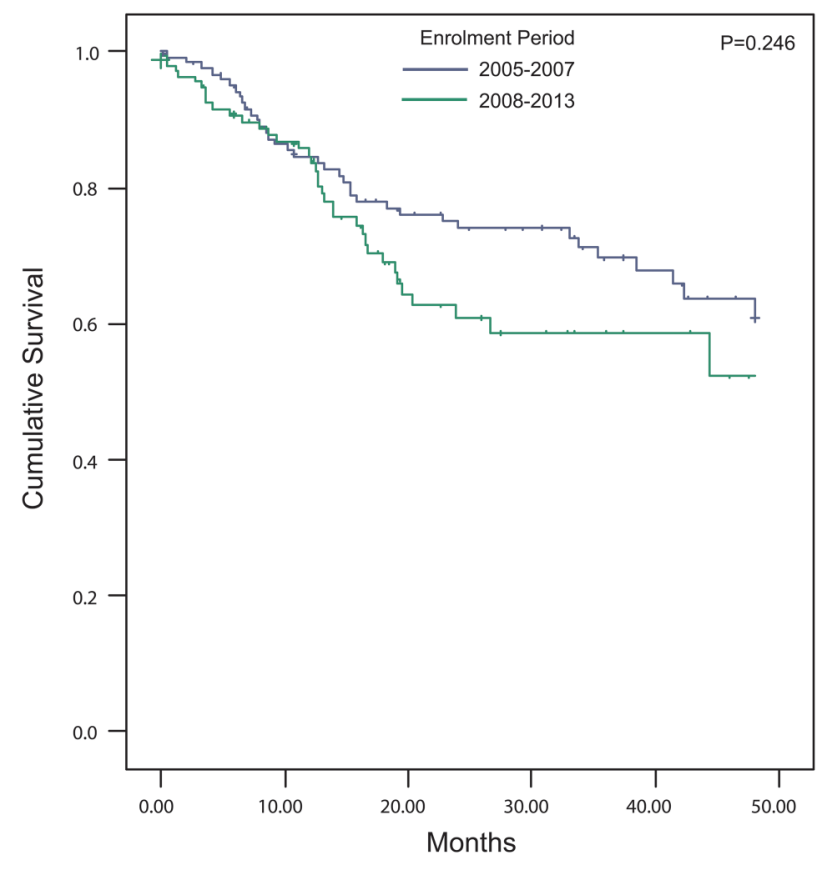

Figure 3 Treatment survival.

months for the total cohort, with a probability of retention of $78.3 \%$ and $60.1 \%$ at 12 and 24 months, respectively, and time to discontinuation due to lack/loss of response, disease progression, $\mathrm{AE}$ or change in therapy was $50.6(46.3-55.1)$ months. No significant differences between enrolment periods were observed (figure 3). However, concomitant use of methotrexate was associated with significantly higher durability of IFX treatment (HR (95\% CI) 0.63 (0.41 to 0.95)).

A total of 1153 AEs were reported by 175 (54.7\%) patients, the majority of which $1107(96.0 \%)$ were nonserious as per the judgement of the treating physician. Table 2 describes AEs occurring in $\geq 2 \%$ of patients. The most frequently reported AEs were arthralgia $(8.1 \%$ of patients), back pain $(7.5 \%)$, nasopharyngitis $(6.9 \%)$ and pain in extremities (5.9\%). Infusion-related reactions were reported for $2.9 \%$ of patients. Overall, no significant differences in the profile and incidence of AEs was observed between enrolment periods with the exception of pain $(7.9 \%$ vs $1.7 \%$; $=0.016)$ and neck pain $(7.9 \%$ vs $1.1 \% ; \mathrm{p}=0.006)$, which were higher in the 2005-2007 enrolment period.

A total of 43 SAEs were reported for 26 (8.1\%) patients (table 3); 23 SAEs occurred for patients enrolled in the 2005-2007 period and 20 occurred in the 2008-2013 enrolment period. There were two serious infections, one was a kidney infection and the other was a urinary tract infection both occurring in the 2008-2013 enrolment period. No tuberculosis cases or malignancies were observed.

\section{DISCUSSION}

The goals of this study were to describe the profile of patients with AS treated with IFX between 2005-2007 
Table 2 AEs occurring in $\geq 2 \%$ of patients-safety population

\begin{tabular}{|c|c|c|c|c|c|c|}
\hline \multirow[b]{3}{*}{ Preferred term* } & \multicolumn{4}{|c|}{ Enrolment period } & \multirow{2}{*}{\multicolumn{2}{|c|}{ Total }} \\
\hline & \multicolumn{2}{|c|}{$2005-2007$} & \multicolumn{2}{|l|}{ 2008-2013 } & & \\
\hline & $\begin{array}{l}\text { Percent of } \\
\text { patients } †\end{array}$ & $\begin{array}{l}\text { Number } \\
\text { of AEs }\end{array}$ & $\begin{array}{l}\text { Percent of } \\
\text { patients } †\end{array}$ & $\begin{array}{l}\text { Number } \\
\text { of AEs }\end{array}$ & $\begin{array}{l}\text { Percent of } \\
\text { patients } †\end{array}$ & $\begin{array}{l}\text { Number } \\
\text { of AEs }\end{array}$ \\
\hline Total & 56.4 & 650 & 53.3 & 503 & 54.7 & 1153 \\
\hline Arthralgia & 9.3 & 30 & 7.2 & 35 & 8.1 & 64 \\
\hline Back pain & 9.3 & 33 & 6.1 & 18 & 7.5 & 51 \\
\hline Pain in extremity & 6.4 & 18 & 5.6 & 21 & 5.9 & 39 \\
\hline Nasopharyngitis & 8.6 & 20 & 5.6 & 14 & 6.9 & 34 \\
\hline Fatigue & 6.4 & 23 & 2.2 & 5 & 4.1 & 28 \\
\hline Neck pain & 7.9 & 20 & 1.1 & 3 & 4.1 & 23 \\
\hline Sinusitis & 5.0 & 14 & 6.1 & 8 & 5.6 & 22 \\
\hline Hypoaesthesia & 5.0 & 10 & 2.8 & 12 & 3.8 & 22 \\
\hline Nausea & 4.3 & 13 & 2.8 & 8 & 3.4 & 21 \\
\hline Pain & 7.9 & 18 & 1.7 & 3 & 4.4 & 21 \\
\hline Upper respiratory tract infection & 5.7 & 12 & 3.9 & 7 & 4.7 & 19 \\
\hline Diarrhoea & 3.6 & 5 & 4.4 & 13 & 4.1 & 18 \\
\hline Headache & 5.0 & 10 & 3.9 & 8 & 4.4 & 18 \\
\hline Pruritus & 4.3 & 9 & 3.9 & 9 & 4.1 & 18 \\
\hline Rash & 5.7 & 13 & 1.7 & 4 & 3.4 & 17 \\
\hline Oropharyngeal pain & 3.6 & 13 & 1.7 & 3 & 2.5 & 16 \\
\hline Infusion-related reaction & 3.6 & 6 & 2.2 & 9 & 2.8 & 15 \\
\hline Chest pain & 2.1 & 6 & 2.8 & 8 & 2.5 & 14 \\
\hline Dyspepsia & 2.9 & 9 & 1.7 & 5 & 2.2 & 14 \\
\hline Hepatic enzyme increased & 2.1 & 4 & 3.9 & 10 & 3.1 & 14 \\
\hline Urinary tract infection & 3.6 & 7 & 2.2 & 7 & 2.8 & 14 \\
\hline Cough & 2.1 & 3 & 3.9 & 10 & 3.1 & 13 \\
\hline Pharyngitis & 4.3 & 6 & 2.2 & 7 & 3.1 & 13 \\
\hline Musculoskeletal stiffness & 1.4 & 5 & 2.8 & 7 & 2.2 & 12 \\
\hline Uveitis & 2.9 & 7 & 2.2 & 5 & 2.5 & 12 \\
\hline Gastroenteritis & 5.7 & 9 & 1.1 & 2 & 3.1 & 11 \\
\hline Influenza & 5.7 & 8 & 1.7 & 3 & 3.4 & 11 \\
\hline Fever & 3.6 & 8 & 1.1 & 2 & 2.2 & 10 \\
\hline Vomiting & 2.9 & 4 & 3.3 & 6 & 3.1 & 10 \\
\hline Fall & 2.9 & 4 & 1.7 & 5 & 2.2 & 9 \\
\hline Hypertension & 4.3 & 7 & 1.1 & 2 & 2.5 & 9 \\
\hline Ear infection & 2.9 & 4 & 1.7 & 3 & 2.2 & 7 \\
\hline
\end{tabular}

and 2008-2013 and to assess the effectiveness and the safety of IFX in routine clinical practice over a 48-month period. Mean (SD) disease duration at IFX initiation in the current study was 9.6 (10.0) years which is comparable with that reported in the Anti-TNF Treatment of RA (ATTRA) registry (8.1 (6.9) years). ${ }^{32}$ Other biological treatment registries, such as Turkey's Turkiye Romatizma Arastirma Savas Dernegi-Izlem Programi (TRASD-IP), ${ }^{33}$ Spain's national registry of spondyloarthropathies (REGISPONSER), ${ }^{25}$ Denmark's Danish Rheumatologic Database (DANBIO) ${ }^{34}$ and Czech Republic's ATTRA ${ }^{32}$ have reported disease durations that varied from $5.0^{35}$ to 15.5 years. ${ }^{36} 37$ One-year and 2-year retention was $78.3 \%$ and $60.1 \%$, respectively, which is comparable with the first course biological retention rate reported for the DANBIO registry (2-year retention: 58\%) but lower than that reported for ATTRA (1-year retention: 84\%; 2-year retention: $76 \%) .{ }^{32} 34$ These differences could possibly be attributed in differences in patient management such as the concomitant use of methotrexate which was identified as a predictor of improved IFX treatment durability. This association has been previously shown and might be due to the improved persistence with anti-TNF treatment in patients with AS treated concomitantly with DMARDs previously described. ${ }^{38} 39$

Subgroup analysis by enrolment period showed that the profile of patients initiating treatment with IFX in Canadian routine care has changed towards less severe disease, shorter disease duration and lower number of prior DMARDs in recent years. The shorter disease duration in the recent enrolment period may be due to changes in patient management involving the earlier initiation of biologicals or an overall increased awareness 
Table 3 SAEs of interest-safety population

\begin{tabular}{|c|c|c|}
\hline \multirow[b]{2}{*}{ Preferred term* } & \multicolumn{2}{|l|}{ Total } \\
\hline & $\begin{array}{l}\text { Percent of } \\
\text { patients } \dagger\end{array}$ & $\begin{array}{l}\text { Number } \\
\text { of SAEs }\end{array}$ \\
\hline Total & 8.1 & 43 \\
\hline Abdominal pain & 0.3 & 1 \\
\hline Aortic aneurysm & 0.3 & 1 \\
\hline Arthralgia & 0.3 & 1 \\
\hline Arthritis & 0.3 & 1 \\
\hline Atrial fibrillation & 0.3 & 1 \\
\hline Back pain & 0.3 & 1 \\
\hline Breast hyperplasia & 0.3 & 1 \\
\hline Cerebrovascular accident & 0.3 & 1 \\
\hline Chest discomfort & 0.3 & 2 \\
\hline Chest pain & 0.3 & 1 \\
\hline Concussion & 0.3 & 1 \\
\hline Coronary artery bypass & 0.3 & 1 \\
\hline Depression & 0.3 & 1 \\
\hline Dyspnoea & 0.3 & 1 \\
\hline Fall & 0.3 & 1 \\
\hline Gastrointestinal inflammation & 0.3 & 1 \\
\hline Hip arthroplasty & 0.3 & 1 \\
\hline Hot flush & 0.3 & 1 \\
\hline Infusion-related reaction & 0.3 & 1 \\
\hline $\begin{array}{l}\text { International normalised ratio } \\
\text { increased }\end{array}$ & 0.3 & 1 \\
\hline Interstitial lung disease & 0.3 & 1 \\
\hline Intestinal obstruction & 0.6 & 2 \\
\hline Kidney infection & 0.3 & 1 \\
\hline Myocardial infarction & 0.3 & 1 \\
\hline Nephrolithiasis & 0.3 & 1 \\
\hline Neuropathy peripheral & 0.3 & 1 \\
\hline Ovarian cyst ruptured & 0.3 & 1 \\
\hline Pleural effusion & 0.3 & 1 \\
\hline Pneumothorax & 0.3 & 1 \\
\hline Pulmonary mass & 0.3 & 1 \\
\hline Fever & 0.3 & 1 \\
\hline Rash & 0.3 & 1 \\
\hline Rash erythematous & 0.3 & 1 \\
\hline Rash pruritic & 0.3 & 1 \\
\hline Rectal haemorrhage & 0.3 & 2 \\
\hline Skin cyst excision & 0.3 & 1 \\
\hline Thrombophlebitis & 0.3 & 1 \\
\hline Urinary tract infection & 0.3 & 1 \\
\hline Uveitis & 0.3 & 1 \\
\hline Vomiting & 0.3 & 1 \\
\hline \multicolumn{3}{|c|}{$\begin{array}{l}{ }^{*} \text { MedDRA V.13.0. } \\
\text { †Patients experiencing the same AE or SAE multiple times were } \\
\text { only counted once for the corresponding preferred term. } \\
\text { AEs, adverse events; MedDRA, Medical Dictionary for Regulatory } \\
\text { Activities; SAEs, serious adverse events. }\end{array}$} \\
\hline
\end{tabular}

leading to earlier AS diagnosis. Although between-group differences were not observed for gender, the proportion of females was higher than expected given that previous studies have demonstrated that AS predominantly affects males at a ratio of 3:1. ${ }^{40}$ The frequency of concomitant DMARD therapy was relatively low (28.7\%) and comparable between enrolment periods which is in line with previous studies showing that their impact on disease progression is only modest in patients with axial SpA, particularly those with AS. ${ }^{16}{ }^{17}$ Treatment resulted in lower disease activity over 48 months in patients enrolled between 2008 and 2013 suggesting that patients may benefit from earlier treatment with IFX. Treatment with IFX for 6 months resulted in significant improvement in all outcomes which was further sustained until 48 months. With respect to BASDAI, the REGISPONSER registry showed similar improvements assessed over a period of $<5$ years. ${ }^{25}$ The change in BASFI, BASDAI and MDGA during the first 6 months of treatment was also in line with the results observed in the studies conducted by Glintborg et $a l^{34}$ and Haibel et $a l^{36}$ where participants were similarly treated with biological drugs. The Czech national registry showed comparable results in terms of baseline BASDAI, BASFI, HAQ and CRP disease parameters; over 36 months of treatment, the mean (SD) change in BASDAI of 3.0 (2.5) and CRP level of 7.5 (16.2) $\mathrm{mg} / \mathrm{L}$ were also in line with our results over the same time period. ${ }^{32}$ IFX resulted in clinically important improvements for ASDAS, with an increase in the percentage of responders increasing from $56 \%$ at 6 months to $75 \%$ at 48 months. The increased rate of major ASDAS improvement observed in the first 12 months of treatment in patients in the earlier enrolment period could possibly be explained by the higher baseline disease activity in this population.

In the present study, the unemployment rate at baseline was $47.5 \%$ which was similar to that reported in a large cohort study conducted in the UK $(40 \%) .{ }^{42}$ Other European studies have shown that unemployment rates among patients with AS can range from $15 \%$ to $45 \%{ }^{4} 43-45$ The literature has also reported that work disability rates ranged from $3 \%$ after 8 years to $50 \%$ after 45 years of disease in patients with AS. ${ }^{43}$ During the course of our study, a low rate $(1.9 \%)$ of patients became unemployed due to disability while on IFX treatment; while $12.1 \%$ of patients who were unemployed due to disability at baseline returned to work. From a socioeconomic perspective, early initiation of IFX could have implications on the economy, use of healthcare resources and indirect costs associated with physical impairment. ${ }^{4346}$

IFX was generally well tolerated by patients with AS in the current study. The incidence of AEs and SAEs was comparable across enrolment periods, with the exception of pain which was more common in the earlier enrolment period. Serious infections occurred in $0.3 \%$ of patients. No tuberculosis cases or malignancies were observed. The incidence of AEs was lower relative to what has been reported in other studies. ${ }^{47} 48$ The lower incidence rate of AEs in this study may have been caused by patient recall bias given the longer interval between follow-up assessments as compared with randomised controlled trials.

Treatment retention was high with $32.5 \%$ of patients discontinuing treatment after 43 months. Treatment discontinuation due to lack/loss of response or disease 
progression was $11.9 \%$ while $8.8 \%$ were discontinued due to an AE.

Our study has certain limitations. Although several approaches were used to assess disease activity, radiographic images are not collected in BioTRAC, thus not allowing the examination of radiographic progression. In addition, completer analysis was used for the assessment of clinical and patient outcomes; therefore, the treatment effect may have been overestimated because of the healthy worker effect. Safety was assessed with the incidence of physician and patient-reported AEs at every follow-up which may have led to underestimated rates due to patient recall bias. A strength of the study, however, is the large number of patients seen in a realworld setting during routine clinical practice which enhances the generalisability of the data to the target population.

In conclusion, the results of the current study suggest that characteristics of patients with AS at initiation of IFX and patient management by the treating physicians have changed over time. Treatment with IFX was well tolerated and effective in improving clinical parameters, patient-reported outcomes and patient ability to work. Early diagnosis and treatment initiation at the early stages of the disease process may be beneficial in terms of clinical response and patient-reported outcomes which may have significant economic implications.

\author{
Author affiliations \\ ${ }^{1}$ Department of Medicine \& Rheumatology, Memorial University, St. John's, \\ Newfoundland, Canada \\ ${ }^{2}$ Institut de Rhumatologie de Montréal, Montreal, Quebec, Canada \\ ${ }^{3}$ St. Joseph's Hospital, Hamilton, Ontario, Canada \\ ${ }^{4}$ McMaster University, Hamilton, Ontario, Canada \\ ${ }^{5}$ Memorial University of Newfoundland, St. John's, Newfoundland, Canada \\ ${ }^{6}$ Credit Valley Rheumatology, Mississauga, Ontario, Canada \\ ${ }^{7}$ Université de Montréal, Montreal, Quebec, Canada \\ ${ }^{8}$ Maisonneuve-Rosemont Hospital, Montreal, Quebec, Canada \\ ${ }^{9}$ McMaster University, Hamilton, Ontario, Canada \\ ${ }^{10}$ Nanaimo Regional General Hospital, Nanaimo, British Columbia, Canada \\ ${ }^{11}$ University of Alberta, Edmonton, Alberta, Canada \\ ${ }^{12}$ JSS Medical Research Inc., St-Laurent, Quebec, Canada \\ ${ }^{13}$ McGill University, Montreal, Quebec, Canada \\ ${ }^{14}$ Janssen Inc. Medical Affairs, Toronto, Ontario, Canada
}

Contributors All authors satisfy the ICMJE authorship criteria, namely: Substantial contributions to the conception or design of the work (ER, FN, MS), or the acquisition (DS, WGB, MK, AC, MZ, SS, MS, SD, DS), analysis (EP, ER, JSS) or interpretation of data (DS, WGB, MK, AC, MZ, SS, MS, SD, $D S, E P, J S S, V L, A J L, F N, E R, S O, M S)$. Drafting the work or revising it critically for important intellectual content (DS, WGB, MK, AC, MZ, SS, MS, $S D$, DS, EP, JSS, VL, AJL, FN, ER, SO, MS). Final approval of the version published (DS, WGB, MK, AC, MZ, SS, MS, SD, DS, EP, JSS, VL, AJL, FN, $E R, S 0, M S)$. Agreement to be accountable for all aspects of the work in ensuring that questions related to the accuracy or integrity of any part of the work are appropriately investigated and resolved (DS, WGB, MK, AC, MZ, SS, MS, SD, DS, EP, JSS, VL, AJL, FN, ER, SO, MS).

\section{Funding Janssen Inc.}

Competing interests PR has received grants and/or honoraria for his roles as investigator and/or consultant with: Janssen, Abbott, AbbVie, Amgen, BMS, Pfizer, Novartis and Merck. DC has received grants and/or honoraria for his roles as investigator and/or consultant with: Abbott, Amgen, AstraZeneca, BMS, Merck-Schering, Janssen, Lilly, Novartis, Pfizer and Wyeth, Roche, UCB.
WGB has received grants and/or honoraria for his roles as investigator and/or consultant with: Abbvie, Amgen, AstraZeneca, Bristol-Myers Squibb, Celgene, Janssen, Eli Lilly, Novartis, Pfizer, Roche, Servier, UCB, Warner Chilcott. MK has received grants and/or honoraria for his roles as investigator and/or consultant with: Abbvie, Amgen, BMS, Janssen, Lilly, Pfizer, Roche, UCB. AC has received grants and/or honoraria for his roles as investigator and/or consultant with: Abbott, Amgen, BMS, Celgene, Merck-Schering, Janssen, Pfizer and Wyeth, Roche, UCB. MZ has received grants and/or honoraria for his roles as investigator and/or consultant with: Abbvie, Amgen, BMS, Celgene, GSK, JNJ, Lilly, Pfizer, UCB. SS has received grants and/or honoraria for his roles as investigator and/or consultant with: Abbott, Amgen, BMS, Merck-Schering, Janssen, Lilly, Novartis, Pfizer and Wyeth, Roche, UCB. MS has received grants and/or honoraria for his roles as investigator and/or consultant with: Abbvie, Janssen, Amgen, BMS, UCB. SD has received grants and/or honoraria for his roles as investigator and/or consultant with: Abbott, Amgen, AstraZeneca, BMS, Merck-Schering, Janssen, Lilly, Pfizer and Wyeth, Roche, Takeda, UCB. DS has received grants and/or honoraria for his roles as investigator and/or consultant with: Janssen, Abbvie, Pfizer, Amgen, Celgene, Roche, BMS. VL, AJL, FN, SO and MS are employees of Janssen Inc. EP, JSS and ER are employees of JSS Medical Research, the contract research organisation mandated to manage the study and conduct data analysis.

\section{Patient consent Obtained.}

Ethics approval Ethics committee/institutional review board approval was obtained from the respective Research Ethics Boards (REB) of participating institutional sites and a Central Institutional Review Board (IRB Services, Ontario Canada) for private practice sites.

Provenance and peer review Not commissioned; externally peer reviewed.

Data sharing statement No additional data are available.

Open Access This is an Open Access article distributed in accordance with the Creative Commons Attribution Non Commercial (CC BY-NC 4.0) license, which permits others to distribute, remix, adapt, build upon this work noncommercially, and license their derivative works on different terms, provided the original work is properly cited and the use is non-commercial. See: http:// creativecommons.org/licenses/by-nc/4.0/

\section{REFERENCES}

1. Gorman JD, Sack KE, Davis JC Jr. Treatment of ankylosing spondylitis by inhibition of tumor necrosis factor alpha. $N$ Engl J Med 2002;346:1349-56.

2. Braun J. [Ankylosing spondylitis]. MMW Fortschr Med 2009;151:79-83.

3. Khan MA. Update on spondyloarthropathies. Ann Intern Med 2002;136:896-907.

4. Sieper J, Braun J, Rudwaleit M, et al. Ankylosing spondylitis: an overview. Ann Rheum Dis 2002;61(Suppl 3):iii8-18.

5. The Arthritis Society. Ankylosing spondylitis. The Arthritis Society, 2013.

6. Boonen A, Severens JL. Ankylosing spondylitis: what is the cost to society, and can it be reduced? Best Pract Res Clin Rheumatol 2002;16:691-705.

7. Boonen A, van der HD, Landewe R, et al. Direct costs of ankylosing spondylitis and its determinants: an analysis among three European countries. Ann Rheum Dis 2003:62:732-40.

8. Kobelt G, Andlin-Sobocki P, Brophy S, et al. The burden of ankylosing spondylitis and the cost-effectiveness of treatment with infliximab (Remicade). Rheumatology (Oxford) 2004;43:1158-66.

9. Ward MM. Functional disability predicts total costs in patients with ankylosing spondylitis. Arthritis Rheum 2002;46:223-31.

10. Boonen A. Socioeconomic consequences of ankylosing spondylitis. Clin Exp Rheumatol 2002;20:S23-6.

11. Mau W, Listing J, Huscher D, et al. Employment across chronic inflammatory rheumatic diseases and comparison with the general population. J Rheumatol 2005;32:721-8.

12. Barlow $\mathrm{JH}$, Wright $\mathrm{CC}$, Williams $\mathrm{B}$, et al. Work disability among people with ankylosing spondylitis. Arthritis Rheum 2001;45:424-9.

13. Haroon N, Inman RD, Learch TJ, et al. The impact of tumor necrosis factor alpha inhibitors on radiographic progression in ankylosing spondylitis. Arthritis Rheum 2013;65:2645-54.

14. Toussirot $E$, Wendling $D$. Current guidelines for the drug treatment of ankylosing spondylitis. Drugs 1998;56:225-40. 
15. Rudwaleit M, Sieper J. Infliximab for the treatment of ankylosing spondylitis. Expert Opin Biol Ther 2005;5:1095-109.

16. Braun J, Landewe R, Hermann KG, et al. Major reduction in spinal inflammation in patients with ankylosing spondylitis after treatment with infliximab: results of a multicenter, randomized, double-blind, placebo-controlled magnetic resonance imaging study. Arthritis Rheum 2006:54:1646-52.

17. Zochling J. Measures of symptoms and disease status in ankylosing spondylitis: Ankylosing Spondylitis Disease Activity Score (ASDAS) Ankylosing Spondylitis Quality of Life Scale (ASQoL), Bath Ankylosing Spondylitis Disease Activity Index (BASDAI), Bath Ankylosing Spondylitis Functional Index (BASFI), Bath Ankylosing Spondylitis Global Score (BAS-G), Bath Ankylosing Spondylitis Metrology Index (BASMI), Dougados Functional Index (DFI), and Health Assessment Questionnaire for the Spondylarthropathies (HAQ-S). Arthritis Care Res (Hoboken) 2011;63(Suppl 11):S47-58.

18. Maksymowych WP, Jhangri GS, Lambert RG, et al. Infliximab in ankylosing spondylitis: a prospective observational inception cohort analysis of efficacy and safety. J Rheumatol 2002;29:959-65.

19. Stone M, Salonen D, Lax M, et al. Clinical and imaging correlates of response to treatment with infliximab in patients with ankylosing spondylitis. J Rheumatol 2001;28:1605-14.

20. Temekonidis TI, Alamanos Y, Nikas SN, et al. Infliximab therapy in patients with ankylosing spondylitis: an open label 12 month study Ann Rheum Dis 2003;62:1218-20.

21. Van den Bosch F, Kruithof E, Baeten D, et al Effects of a loading dose regimen of three infusions of chimeric monoclonal antibody to tumour necrosis factor alpha (infliximab) in spondyloarthropathy: an open pilot study. Ann Rheum Dis 2000;59:428-33.

22. Braun J, Baraliakos X, Golder W, et al. Magnetic resonance imaging examinations of the spine in patients with ankylosing spondylitis, before and after successful therapy with infliximab: evaluation of a new scoring system. Arthritis Rheum 2003;48:1126-36.

23. Rudwaleit $\mathrm{M}$, Baraliakos $\mathrm{X}$, Listing $\mathrm{J}$, et al. Magnetic resonance imaging of the spine and the sacroiliac joints in ankylosing spondylitis and undifferentiated spondyloarthritis during treatment with etanercept. Ann Rheum Dis 2005;64:1305-10.

24. Vander Cruyssen B, Ribbens C, Boonen A, et al. The epidemiology of ankylosing spondylitis and the commencement of anti-TNF therapy in daily rheumatology practice. Ann Rheum Dis 2007;66: 1072-7.

25. Collantes E, Zarco P, Munoz E, et al. Disease pattern of spondyloarthropathies in Spain: description of the first national registry (REGISPONSER) extended report. Rheumatology (Oxford) 2007;46:1309-15.

26. Dincer U, Cakar E, Kiralp MZ, et al. Diagnosis delay in patients with ankylosing spondylitis: possible reasons and proposals for new diagnostic criteria. Clin Rheumatol 2008;27:457-62.

27. Brandt HC, Spiller I, Song IH, et al. Performance of referral recommendations in patients with chronic back pain and suspected axial spondyloarthritis. Ann Rheum Dis 2007;66:1479-84.

28. Zink A, Thiele $K$, Huscher $D$, et al. Healthcare and burden of disease in psoriatic arthritis. A comparison with rheumatoid arthritis and ankylosing spondylitis. J Rheumatol 2006;33:86-90.

29. Deyo RA, Weinstein JN. Low back pain. N Engl J Med 2001;344:363-70.

30. Rudwaleit M, Listing J, Brandt J, et al. Prediction of a major clinical response (BASDAI 50) to tumour necrosis factor alpha blockers in ankylosing spondylitis. Ann Rheum Dis 2004;63:665-70.

31. Thorne C, Bensen WG, Choquette D, et al. Effectiveness and safety of infliximab in rheumatoid arthritis: analysis from a Canadian multicentre prospective observational registry. Arthritis Care Res (Hoboken) 2014;66:1142-51.

32. Pavelka K, Forejtova S, Stolfa J, et al. Anti-TNF therapy of ankylosing spondylitis in clinical practice. Results from the Czech national registry ATTRA. Clin Exp Rheumatol 2009;27:958-63.

33. Bodur $\mathrm{H}$, Ataman S, Bugdayci DS, et al. Description of the registry of patients with ankylosing spondylitis in Turkey: TRASD-IP. Rheumatol Int 2012;32:169-76.

34. Glintborg B, Ostergaard M, Krogh NS, et al. Clinical response, drug survival and predictors thereof in 432 ankylosing spondylitis patients after switching tumour necrosis factor alpha inhibitor therapy: results from the Danish nationwide DANBIO registry. Ann Rheum Dis 2013;72:1149-55.

35. Brandt J, Haibel H, Cornely D, et al. Successful treatment of active ankylosing spondylitis with the anti-tumor necrosis factor alpha monoclonal antibody infliximab. Arthritis Rheum 2000;43:1346-52.

36. Haibel $\mathrm{H}$, Song $\mathrm{IH}$, Rudwaleit $\mathrm{M}$, et al. Multicenter open-label study with infliximab in active ankylosing spondylitis over 28 weeks in daily practice. Clin Exp Rheumatol 2008;26:247-52.

37. van der Linden SM, Valkenburg HA, de Jongh BM, et al. The risk of developing ankylosing spondylitis in HLA-B27 positive individuals. A comparison of relatives of spondylitis patients with the general population. Arthritis Rheum 1984;27:241-9.

38. Fabbroni M, Cantarini L, Caso F, et al. Drug retention rates and treatment discontinuation among anti-TNF-alpha agents in psoriatic arthritis and ankylosing spondylitis in clinical practice. Mediators Inflamm 2014;2014:862969.

39. Lie E, Kristensen LE, Forsblad-d'Elia $\mathrm{H}$, et al. The effect of comedication with conventional synthetic disease modifying antirheumatic drugs on TNF inhibitor drug survival in patients with ankylosing spondylitis and undifferentiated spondyloarthritis: results from a nationwide prospective study. Ann Rheum Dis 2015;74:970-8.

40. Boonen A, van der Heijde D, Landewe R, et al. Costs of ankylosing spondylitis in three European countries: the patient's perspective. Ann Rheum Dis 2003;62:741-7.

41. Lee W, Reveille JD, Davis JC Jr, et al. Are there gender differences in severity of ankylosing spondylitis? Results from the PSOAS cohort. Ann Rheum Dis 2007;66:633-8.

42. Healey EL, Haywood KL, Jordan KP, et al. Impact of ankylosing spondylitis on work in patients across the UK. Scand J Rheumatol 2011;40:34-40.

43. Boonen A. A review of work-participation, cost-of-illness and cost-effectiveness studies in ankylosing spondylitis. Nat Clin Pract Rheumatol 2006;2:546-53.

44. Boonen A, van der HD, Landewe R, et al. Work status and productivity costs due to ankylosing spondylitis: comparison of three European countries. Ann Rheum Dis 2002;61:429-37.

45. Kobelt G, Andlin-Sobocki P, Maksymowych WP. Costs and quality of life of patients with ankylosing spondylitis in Canada. $J$ Rheumatol 2006;33:289-95.

46. Verstappen SM, Bijlsma JW, Verkleij $\mathrm{H}$, et al. Overview of work disability in rheumatoid arthritis patients as observed in cross-sectional and longitudinal surveys. Arthritis Rheum 2004:51:488-97.

47. Braun J, Brandt J, Listing J, et al. Two year maintenance of efficacy and safety of infliximab in the treatment of ankylosing spondylitis. Ann Rheum Dis 2005;64:229-34.

48. van der Heijde D, Kivitz A, Schiff MH, et al. Efficacy and safety of adalimumab in patients with ankylosing spondylitis: results of a multicenter, randomized, double-blind, placebo-controlled trial. Arthritis Rheum 2006;54:2136-46. 